\title{
Centrally Mediated Vasopressor Effect of Angiotensin II in Man
}

\author{
Hideo Ueda, M.D., Yasumi Uchida, M.D., Keiji Ueda, M.D., \\ Tatsujiro Gondarra, M.D., and Soichi Katayama, M.D.
}

\section{Summary}

Responses to vertebral and aortic injection of synthetized angiotensin II of the systemic arterial pressure and heart rate were examined in humans and the following results werc obtained:

Angiotensin II injections in the dosages from 0.016 to $0.06 \mu \mathrm{g}$. $/ \mathrm{Kg}$. caused the following effects.

1) Vertebral injection produced a higher rise in the systemic arterial pressure than that produced by aortic injection of the same dose.

2) Hcart rate was increased by vertebral injection of a small dose, but was decreased by aortic injection.

From these data, it was considered that vertebral injection of angiotensin II in humans caused a rise in blood pressure partly by increasing the sympathetic nerve activity.

\section{Additional Indexing Words :}

Vertebral and aortic catheterization

$\mathrm{M}$

ANY investigations have been reported concerning the vasopressor effects of angiotensin II. Angiotensin II has a direct peripheral action on the vascular wall, ${ }^{11,2)}$ releases catecholamines from the adrenal medulla, ${ }^{31}$ produces a greater output of noradrenaline at the peripheral nerve endings, ${ }^{4(-8)}$ stimulates directly the post-synaptic neurons in sympathetic ganglia, ${ }^{8)}$ acts on the brain directly or indirectly to increase sympathetic nerve activity ${ }^{91,10), 19)}$ and accordingly elevates blood pressure. ${ }^{11-13)}$ In our previous study, it was reported that vertebral injection of angiotensin II in rabbit produced a higher rise in blood pressure than that produced by injecting the same dose into the descending thoracic aorta or the internal carotid artery. Moreover, vertebral injection in a small dose produced, although not always, an increase in sympathetic discharge under buffer nerve resection, but aortic injection, on the contrary, produced a decrease in sympathetic discharge. ${ }^{9 /, 15\}}$

The present study was carried out to elucidate whether or not a centrally mediated vasopressor effect of angiotensin II exists in humans.

From the Second Department of Internal Medicine, Faculty of Medicine, University of Tokyo, Tokyo.

Received for publication December 14, 1968. 


\section{Methods}

Five normotensive volunteers, 3 men and 2 women, were examined for the present study. The volunteers were catheterized in supine position with local anesthesia by procaine. A catheter (Kifa, green) with side-holes was introduced through the left femoral artery into the left vertebral artery using the Seldinger's method.

The location of the tip of the catheter was identified with the injection of a small dose of sodium iothalamate ( $80 \%$ Angio Conray $\left.{ }^{\circledR}\right)$ through the catheter by a 9 inch image amplifier and monitor television. The blood flow in the vertebral artery was not interrupted by inserting the catheter in all cases. The pressure was recorded by a Statham strain gauge connected to the catheter inserted into the right femoral artery. Angiotensin II in the dosages from 1.0 to $2.5 \mu \mathrm{g}$. $(0.016$ to $0.06 \mu \mathrm{g} . / \mathrm{Kg}$.) dissolved in $1 \mathrm{ml}$. of saline was injected into the vertebral artery. The catheter was then withdrawn to the hilar level in the descending thoracic aorta and angiotensin II was injected again at this level. It was injected in reverse procession in 2 cases. The injections were performed with an interval of about $5 \mathrm{~min}$. after the blood pressure returned to the control level. The maximum rises in systolic and diastolic pressures following the injection were compared respectively to mean values of systolic and diastolic pressures measured $1 \mathrm{~min}$. before the injection. Heart rate during $1 \mathrm{~min}$. following the injection was also compared to that during 1 min. before the injection.

\section{REsults}

The injections of $3 \mathrm{ml}$. of saline, Ringer's solution or $5 \%$ glucose into the vertebral artery produced little influence on blood pressure and heart rate. On the contrary, the injections of angiotensin II into the vertebral artery produced higher rises both in systolic and diastolic pressures than those produced by aortic injections of the same doses (Table I). In a 35-year-old male (H.K.), vertebral injection of $2.5 \mu \mathrm{g}$. produced a marked rise in blood pressure, but aortic injection, on the contrary, produced no significant rise in blood pressure (Table 1). Percent changes in blood pressure produced by vertebral injection were larger than those produced by aortic injection in all cases (Fig. I). One $\mu \mathrm{g}$. of angiotensin II injected into the vertebral artery caused an increase in heart rate, while the injection of the same dose into the aorta caused its decrease. Vertebral injection of $2.5 \mu \mathrm{g}$. caused an increase in heart rate in 4 out of 6 trials in 4 cases, aortic injection of the same dose, on the contrary, caused a decrease in all 4 trials in 4 cases (Fig. 2, Table I).

\section{Discussion}

In the present studies, vertebral injection of angiotensin II in a small dose produced a higher rise in blood pressure than that produced by aortic injection of the same dose. Like in man in this study, vertebral injection in 
Table I. The Data Calculated from the Recordings

\begin{tabular}{|c|c|c|c|c|c|c|c|c|c|c|c|}
\hline & & \multicolumn{2}{|l|}{ HR } & & \multicolumn{2}{|c|}{ SBP } & & \multicolumn{2}{|c|}{ DBP } & \\
\hline & & & B & $\mathrm{A}$ & & B & A & & B & A & \\
\hline \multirow{4}{*}{$1.0 \mathrm{pg}}$. & \multirow{2}{*}{ H.K. } & V & 64 & 69 & +5 & 95 & 130 & +35 & 55 & 80 & +25 \\
\hline & & A & 78 & 70 & -8 & 110 & 120 & +10 & 55 & 70 & +15 \\
\hline & \multirow{2}{*}{ K.M. } & V & 72 & 104 & +32 & 130 & 155 & +25 & 50 & 80 & +30 \\
\hline & & A & 74 & 72 & -2 & 119 & 135 & +19 & 50 & 60 & +10 \\
\hline & \multirow{2}{*}{ H.K. } & V & 66 & 72 & +6 & 116 & 115 & +39 & 57 & 90 & +33 \\
\hline & & A & 75 & 66 & -9 & 108 & 110 & +2 & 52 & 57 & +5 \\
\hline & \multirow{2}{*}{ K.M. } & V & 105 & 99 & -4 & 128 & \multirow[t]{2}{*}{180} & \multirow[t]{2}{*}{+52} & \multirow[t]{2}{*}{64} & \multirow[t]{2}{*}{80} & \multirow[t]{2}{*}{+16} \\
\hline & & A & i & & & 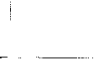 & & & & & \\
\hline \multirow{8}{*}{$2.5 \mu \mathrm{g}}$. & \multirow{2}{*}{ M.N. } & $\mathrm{V}$ & 78 & 71 & -7 & 130 & 220 & +90 & 65 & 110 & +45 \\
\hline & & A & 78 & 55 & -23 & 115 & 185 & +70 & 75 & 110 & +30 \\
\hline & \multirow{4}{*}{ E.M. } & V & 70 & 74 & +4 & 158 & 220 & +62 & 66 & 105 & +39 \\
\hline & & A & 73 & 64 & -9 & 156 & 195 & +39 & 67 & 90 & +23 \\
\hline & & V & 66 & 72 & +6 & 145 & 215 & +70 & 60 & 100 & +40 \\
\hline & & A & & & & & & & & & \\
\hline & \multirow{3}{*}{ H.N. } & $\mathrm{V}$ & 73 & 77 & +4 & 144 & 215 & +71 & 82 & 110 & +28 \\
\hline & & A & 79 & 72 & -7 & 140 & 205 & +65 & 74 & 95 & +21 \\
\hline & & & $(\min )$. & mean & & $\mathrm{BP}(\mathrm{mm}$ & $\mathrm{Hg})$ & mean & $\mathrm{DBP}(\mathrm{m}$ & a. $\mathrm{Hg}$ ) & mean \\
\hline \multirow{2}{*}{$1.0 \mu \mathrm{g}}$. & \multirow{2}{*}{$\begin{array}{l}\text { V } \\
\text { A }\end{array}$} & +5 & $\sim+32$ & \multirow{2}{*}{\multicolumn{2}{|c|}{$\begin{array}{c}+18.5 \\
-5\end{array}$}} & \multirow{2}{*}{$\begin{array}{l}+25 \sim \\
+10: 2\end{array}$} & +35 & +30 & \multicolumn{2}{|c|}{$+25 \sim+30$} & +27.5 \\
\hline & & -2 & $\sim \quad-8$ & & & & +19 & +14.5 & $+10 \sim$ & +15 & +12.5 \\
\hline \multirow{2}{*}{$2.5 \mu \mathrm{g}$. } & \multirow{2}{*}{$\begin{array}{l}\text { V } \\
\text { A }\end{array}$} & -7 & +6 & \multirow{2}{*}{\multicolumn{2}{|c|}{$\begin{array}{l}+1.6 \\
-12\end{array}$}} & \multirow{2}{*}{$\begin{array}{l}+39 \sim \\
+2 \sim\end{array}$} & +90 & \multirow{2}{*}{$\begin{array}{l}+64 \\
+19\end{array}$} & $+16 \sim$ & +45 & +33.5 \\
\hline & & -7 & $\sim-23$ & & & & +70 & & $+5 \sim$ & +30 & +20.2 \\
\hline
\end{tabular}

$\mathrm{V}$ and $\mathrm{A}$ : vertebral and aortic injections.

$B$ and $A$ in HR: number of heart beats in one minute before and after the injection, respectively.

$B$ and $A$ in SBP: mean systolic pressure before and after the injection, respectively.

$B$ and $A$ in $D B P$ : mean diastolic pressure before and after the injection, respectively,

rabbit produced a higher rise than that produced by aortic injection; the latter, on the other hand, was usually higher than that produced by carotid injection. ${ }^{93,103,12), 13)}$ Moreover, vertebral injection of angiotensin II in a small dose in our previous experiments resulted, although not always, in an increasc in sympathetic discharge, whereas aortic injection caused its decrease. ${ }^{9,10 !}$ Uramoto observed that vertebral injection of nicotine, ephedrine or $\mathrm{KCl}$ caused more easily a rise in blood pressure, but carotid injection, on the contrary, more easily a fall in blood pressure. ${ }^{14}$ Vertebral embolism caused an increase in 


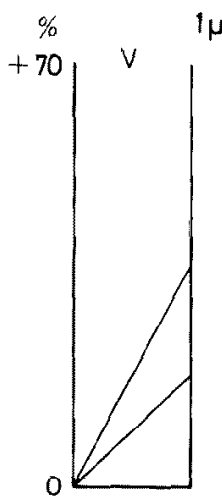
$\mu g$.
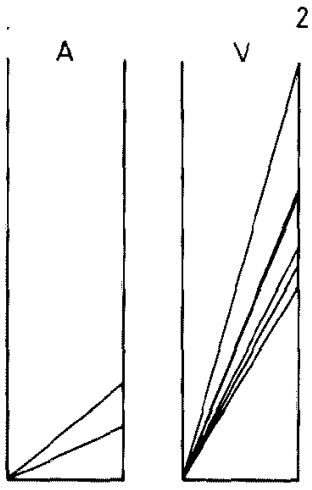

$2.5 \mu \mathrm{g}$.

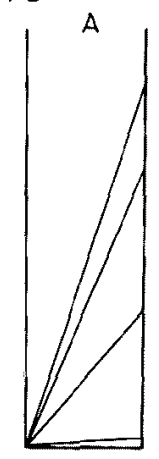

Fig. 1. Percent changes in systolic arterial pressure before and after $V$ : vertebral injection and $\mathrm{A}$ : aortic injection of angiotensin II.
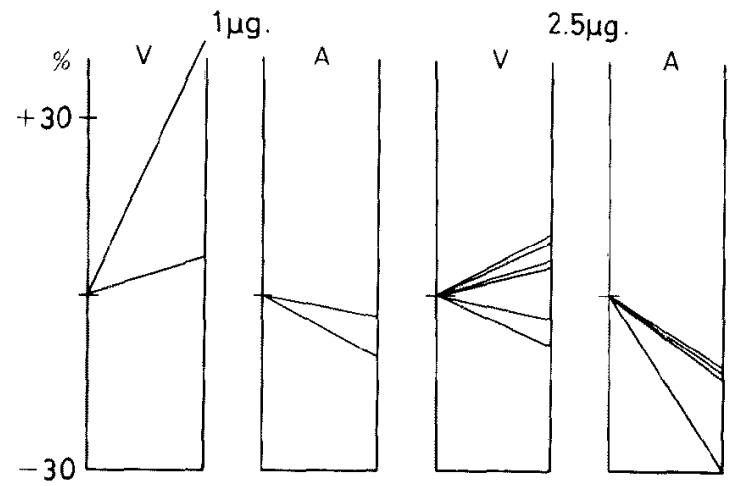

Fig. 2. Percent changes in heart rate before and after $V:$ vertebral injection and $\mathrm{A}$ : aortic injection of angiotensin II.

cardiac and renal sympathetic nerve activity followed by hypertension, but carotid embolism, although not always, a decrease in the activity followed by hypotension in the previous studies done in rabbits by the authors. ${ }^{15), 17)}$

These findings in animals indicate that sympathetico-excitatory function is dominant in the portions supplied by the vertebral arteries, whereas sympathetico-inhibitory function is dominant in the portions supplied by the internal carotid arteries.

Heart rate increased following vertebral injection of $1.0 \mu \mathrm{g}$. of angiotensin II in the present studies. Heart rate is controlled both by sympathetic and vagal nerves. The former accelerates but the latter, although it contains some cardio-accelerator fibers, ${ }^{16)}$ as a whole inhibits heart beat.

Therefore, the findings of increased heart rate following vertebral injection in humans support the possibility of increased sympathetic nerve activity which contributed, at least in a part, to produce an increase in blood pressure 
and heart rate.

On the other hand, decreased heart rate following aortic injection might be due to reflex inhibition of sympathetic nerve activity.

The findings of decreased heart rate following vertebral injection of an increased dosc of angiotensin II $(2.5 \mu \mathrm{g}$.) in 2 of 6 trials, although slight as compared to that produced by aortic injection, might be causcd by reflex sympathetico-inhibitory effect through the buffer nerves which overcame the centrally mediated sympathetico-excitatory effect.

It is still to be clarified by what mechanism vertebral injection of angiotensin II increases sympathetic outflow. Anoxia due to basilar artery constriction by the substance ${ }^{18}$ ) or the direct effect of this substance on the chemoreceptor in the brain stem might concern to this phenomenon. ${ }^{19}$ )

\section{References}

1. Yonkman, F. F.: Proc. Soc. Exp. Biol. 54: 204, 1943.

2. De Pasqualo, N. P. and Burch, G. E.: Circulat. Res, 13: 239, 1963.

3. Feldberg, W. and Lewis, G. P.: J. Physiol. 171: 98, 1964.

4. Benelli, G. D., Della, Bella, and Gandini, A.: Brit. J. Pharmacol. 22: $211,1964$.

5. Leverty, R.: J. Pharm. Pharmacol. 15: 63, 1963.

6. Zimmerman, B. G.: Circulat. Res. 11: 780, 1962.

7. McGriff, J. G. and Itskovitz, H. D.: J. Glin. Invest. 43: 2359, 1964.

8. Lewis, G. P. and Reit, E. J.: J. Physiol. 179: 538, 1965.

9. Ueda, H., Uchida, Y., and Ozeki, K.: Jap. Circulat. J. 31 ; 849, 1967.

10. Ueda, H., Uchida, Y., and Ozeki, K.: Jap. Circulat. J. 31 : 1282, 1967.

11. Bickerton, R. K. and Buckley, J. P.: Proc. Soc. Exp. Biol. 106: 834, 1961.

12. Dickinson, C. J. and Lawrence, J. R.: Lancet i: 1354, 1963.

13. Yu, R. and Dickinson, C. J.: Lancet ii: 1276, 1965.

14. Uramoto, R.: Igakukenkyu 26: 1611, 1956.

15. Ueda, H. and Uchida, Y.: Jap. Circulat. J. 31 : 1283, 1967.

16. Kabat, H.: Am. J. Physiol. 128: 246, 1939.

17. Ueda, H. and Uchida, Y.: Autonomic Neruous System 5: 57, 1958.

18. Katsuki, S., Iino, K., and Tanaka, J: Fukuoka acta Med. 55: 908, 1964.

19. Ueda, H., et al.: Autonomic Nervous System 5: 57, 1958. 